\title{
Article \\ Buckling Test of Composite Cylindrical Shells with Large Radius Thickness Ratio
}

\author{
Atsushi Takano ${ }^{1, *}$, Ryuta Kitamura ${ }^{1}$, Takuma Masai ${ }^{2}$ and Jingxuan Bao ${ }^{3}$ \\ 1 Department of Mechanical Engineering, Kanagawa University, 3-27-1, Rokkakubashi, Kanagawa-ku, \\ Yokohama 221-8686, Japan; ft102093gj@kanagawa-u.ac.jp \\ 2 Research Institute for Engineering, Kanagawa University, 3-27-1, Rokkakubashi, Kanagawa-ku, \\ Yokohama 221-8686, Japan; zvu07747@nifty.com \\ 3 Graduate School of Engineering, Kanagawa University, 3-27-1, Rokkakubashi, Kanagawa-ku, \\ Yokohama 221-8686, Japan; r201970120ac@jindai.jp \\ * Correspondence: atakano@kanagawa-u.ac.jp; Tel.: +81-45-481-5661 (ext. 3371)
}

check for updates

Citation: Takano, A.; Kitamura, R.; Masai, T.; Bao, J. Buckling Test of Composite Cylindrical Shells with Large Radius Thickness Ratio. Appl. Sci. 2021, 11, 854. https://doi.org/ 10.3390/app11020854

Received: 9 December 2020

Accepted: 14 January 2021

Published: 18 January 2021

Publisher's Note: MDPI stays neutral with regard to jurisdictional claims in published maps and institutional affiliations.

Copyright: (c) 2021 by the authors. Licensee MDPI, Basel, Switzerland. This article is an open access article distributed under the terms and conditions of the Creative Commons Attribution (CC BY) license (https:/ / creativecommons.org/licenses/by/ $4.0 /)$.
Featured Application: Thin-walled composite cylindrical shells, due to their light weight, high stiffness and strength, can be applied to ultra-light weight rockets, fuselages of airplanes, satellites, and spacecraft.

\begin{abstract}
A buckling test of composite cylindrical shells with a radius-thickness ratio $(r / t)=893$ under axial compression was conducted to investigate the effects of the radius-thickness ratio $(r / t)$. It is known that the buckling load of cylinders shows large differences and scatter between theory and experiment. The ratio of the experimental buckling load and theoretical buckling load is called the knockdown factor (KDF). Many investigations have been conducted to find the cause of the degradation and scatter in the KDF, but as yet, no cause has been found. In 1968, NASA's buckling design criterion, NASA SP-8007, gave an empirical KDF curve that decreased with the increasing $r / t$ (up to 2000) for metal cylinders. The same curve has been applied to composite cylinders. Recently, Takano derived a flat lower-bound KDF in terms of A- and B-basis values $(99 \%$ and $90 \%$ probability with a $95 \%$ confidence level) through a statistical analysis of experimental buckling loads. The result, however, based on experimental results up to $r / t=500$ and, thus, the dependency on a large range of $r / t$, is not clear. Thus, the authors focused on a larger range of $r / t$. Cylindrical shells made from carbon fiber-reinforced plastic (CFRP) were tested. The nominal radius, thickness, and length were $r=100.118 \mathrm{~mm}, t=0.118 \mathrm{~mm}$, and $L=200 \mathrm{~mm}$ and, thus, the $r / t=848$ and length-to-radius ratio $(L / r)=2$.0. Shape imperfections were also measured by using in-house laser displacement equipment. The buckling load was slightly affected by the $r / t$, but the reduction in the KDF was insignificant.
\end{abstract}

Keywords: buckling; shell; knockdown factor

\section{Introduction}

The scatter and deviation of the buckling load between theory and experiment have been studied since the 1960s, but the cause of the scatter and deviation has yet to be revealed. One potential cause is thought to be shape imperfection. Studies using a nonlinear finite element analysis, including of the measured shape imperfection, have given 5-10\% larger results than the experimental buckling loads [1]. The method, however, cannot be used for prediction, because it requires the manufacturing of a cylinder and measurement of the shape imperfection. Regression analyses have further shown that various factors, including layup overlaps or gaps, the radius-to-thickness ratio $(r / t)$, the length-to-radius ratio $(L / r)$ [2], layup stiffness, and oval shape imperfection, are not statistically significant [3]. The authors investigated the effect of axisymmetric shape imperfections on the ratio of the experimental buckling load and theoretical buckling load, which is called the knockdown factor (KDF), and found that it increases with the amplitude of drum-type 
shape imperfections [4]. The investigation was conducted on nine cylinders; however, they were of the same radius $r=75 \mathrm{~mm}$, and their $r / t$ values were similar, i.e., from 460 to 670. On the other hand, many metal cylinders were investigated over a wide range of $r / t$ (the data summarized in Reference [5]), and it was found that the KDF decreased with the increasing $r / t$ [6], as shown in Figure 1.

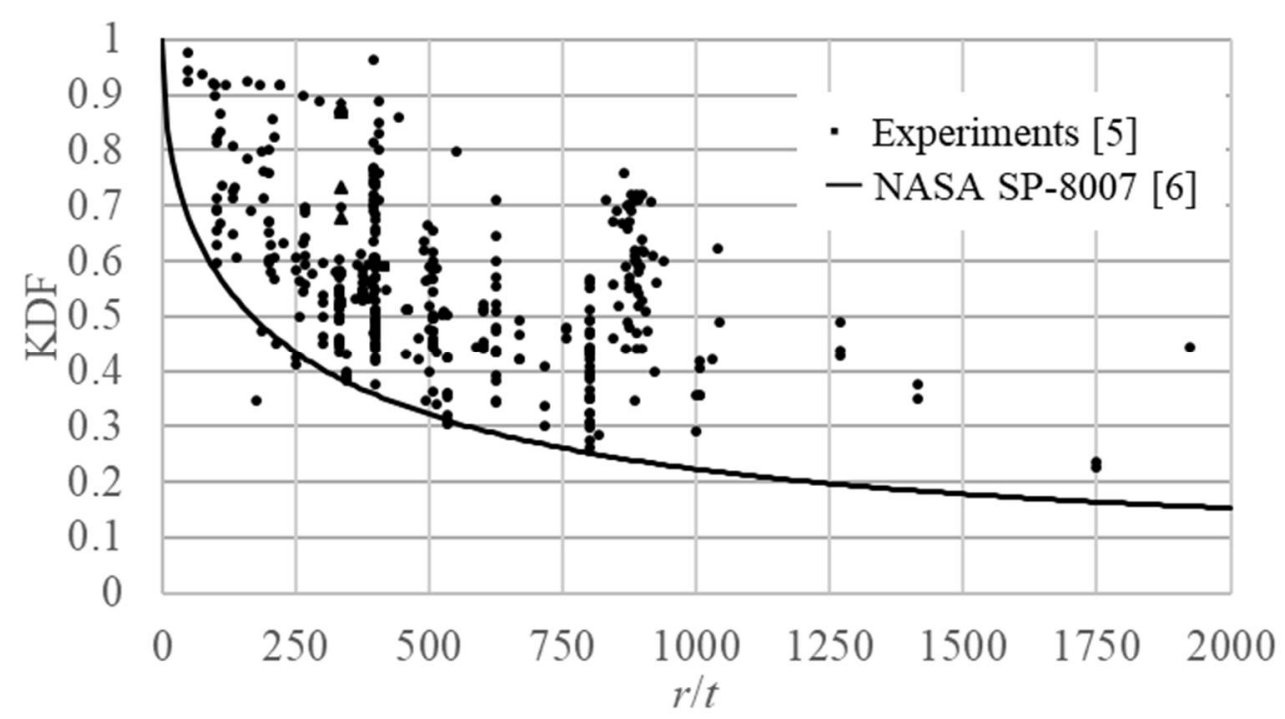

Figure 1. The knockdown factor (KDF) of the metal cylinders. $r / t$ : radius-to-thickness ratio $[5,6]$.

Composite cylinders, however, show a constant relation between the KDF and $r / t$ in a narrow range of $r / t$ [7] (as shown later). Recently, several studies for the KDF of cylinders have been published; however, there was no study for a composite cylinder with the range of a $r / t$ over 670 [8-14]. Wagner et al. [8] investigated the KDF of metal cylinders with single boundary perturbation approach. Wagner and Hühne's [9] discussion about that led to new, improved knockdown factors for the design of cylindrical metal shells under axial compression. Tobias and Dieter [10] investigated the relationship between geometric imperfection and the KDF. Wagner et al. [11] presented a numerical design approach based on the reduced stiffness method for the buckling of shell structures. Although a lot of effort has gone into developing novel manufacturing and the production of composites [15-18], there has been no investigation into the KDF of composite tubes. Thus, the aim of the current study was to investigate the KDF over a large range of a $r / t$ through buckling tests with $r=100 \mathrm{~mm}, t=0.112 \mathrm{~mm}$, and $r / t=893$. Moreover, the effect of the shape imperfections was measured before and after the buckling tests, and the relationship between the shape imperfections and the KDF was investigated.

\section{Test Specimens}

\subsection{Materials and Properties}

Two cylindrical specimens (No. 191 and No. 192) were made from carbon fiberreinforced plastic (CFRP) pre-preg HSX350C075S (Mitsubishi Chemical Co. Ltd., Hong Kong, China). Table 1 shows the material properties, and Table 2 shows the configurations of the specimens.

\subsection{Manufacturing of Cylindrical Specimens}

As shown in Figure 2, the cylinders were highly flexible and easily deformed by touch. Thus, to apply a compression load and keep the cylindrical shape, aluminum alloy end rings were bonded to the cylinders by using a bonding fixture, as shown in Figure 3. The bonding fixture aligned the center axis of both end rings without inclination. First, a fixture ring was set on the baseplate of the fixture, and then, the cylindrical specimen was set into the 2-mm-wide slot of the end ring, as shown in Figure 4. The cylindrical specimen was 
fixed using the alignment ring, as shown in Figure 5, and then, adhesive (AW106/HY953) was applied by syringe. To prevent thermal residual stress, the adhesive was cured at room temperature. After curing, the specimen with the bonded ring was removed, and the other end ring was set on the baseplate of the bonding fixture. Then, the other end of the specimen was inserted into the slot of the ring on the baseplate, and the bonded ring was fixed to the alignment plate, as shown in Figure 6. Adhesive was then applied to the ring on the baseplate by syringe, and it was cured at room temperature. The cylindrical specimen with both end rings is shown in Figure 7.

Table 1. Material properties of HSX350C075S carbon fiber-reinforced plastic (CFRP).

\begin{tabular}{cc}
\hline Property & Value \\
\hline Ply thickness $(\mathrm{mm})$ & 0.056 \\
Young modulus of fiber direction $E_{L}(\mathrm{GPa})$ & 257.4 \\
Young modulus of transverse direction $E_{T}(\mathrm{GPa})$ & 6.770 \\
Shear modulus, $G_{L T}(\mathrm{MPa})$ & 4.495 \\
Poisson's ratio $v_{L T}(-)$ & 0.33 \\
\hline
\end{tabular}

Table 2. Configuration of the cylindrical specimens. $L / r$ : length-to-radius ratio and $r / t$ : radius-tothickness ratio.

\begin{tabular}{cc}
\hline Property & Value \\
\hline Laminate sequence & $(-50 / 50)$ \\
Radius, $r(\mathrm{~mm})$ & 100 \\
Thickness, $t(\mathrm{~mm})$ & 0.112 \\
Length, $L(\mathrm{~mm})$ & 200 \\
$L / r$ & 2 \\
$r / t$ & 893 \\
\hline
\end{tabular}

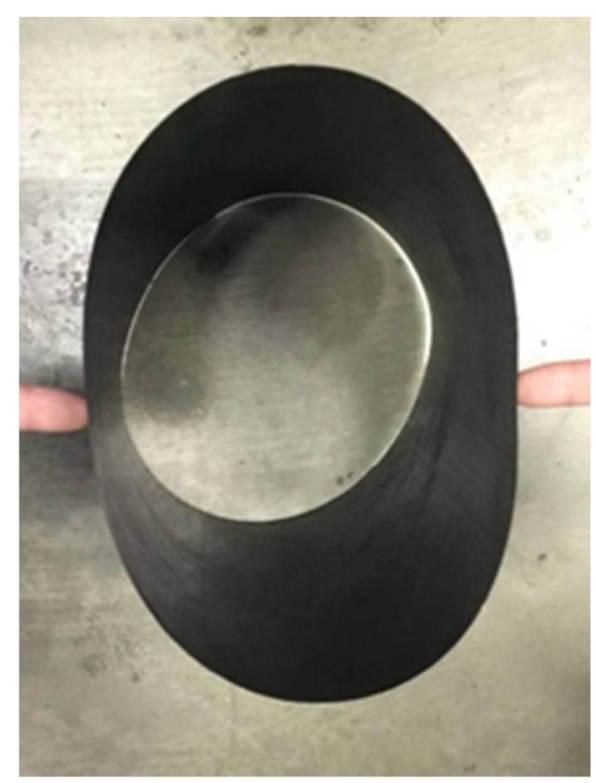

Figure 2. Cylindrical specimen deformed by touch. 


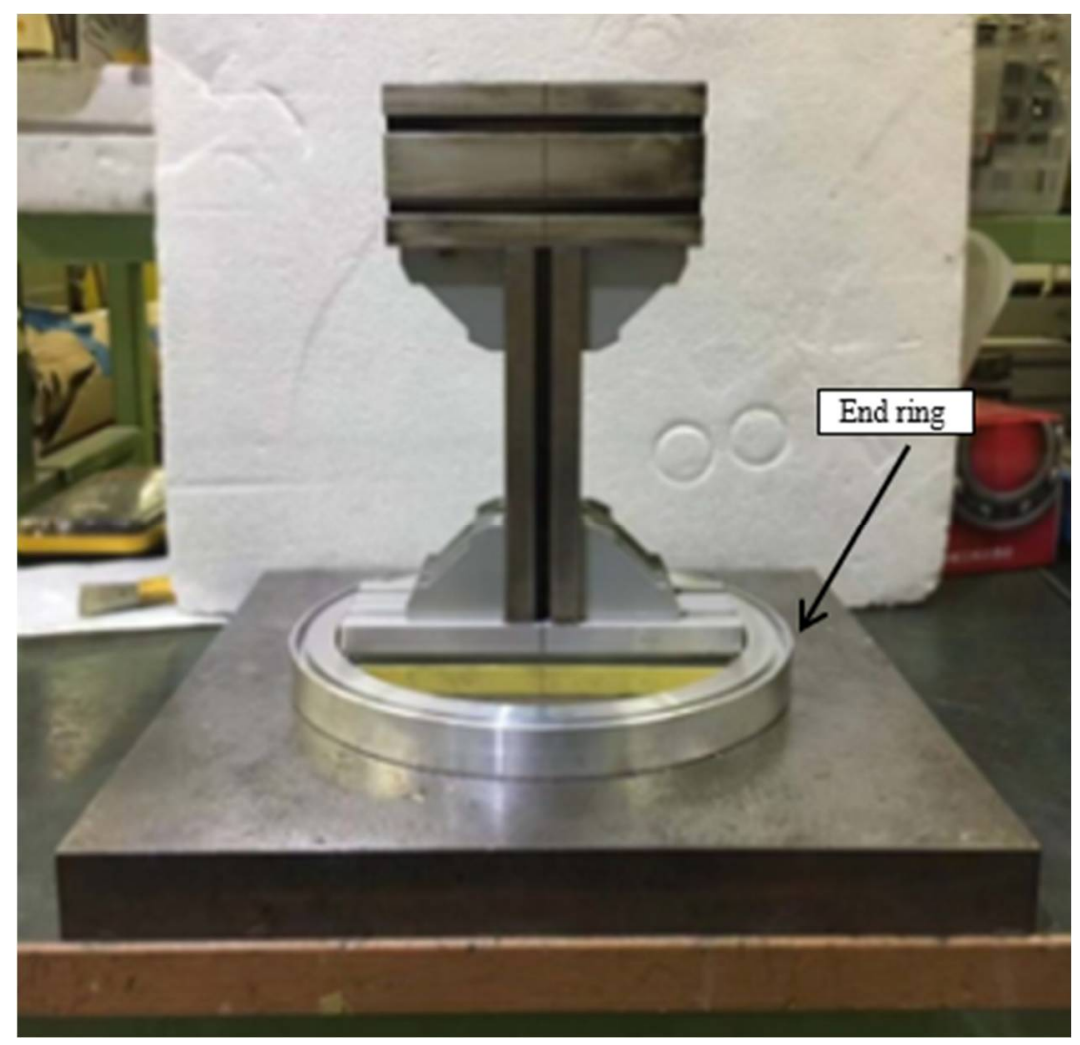

Figure 3. Bonding fixture.

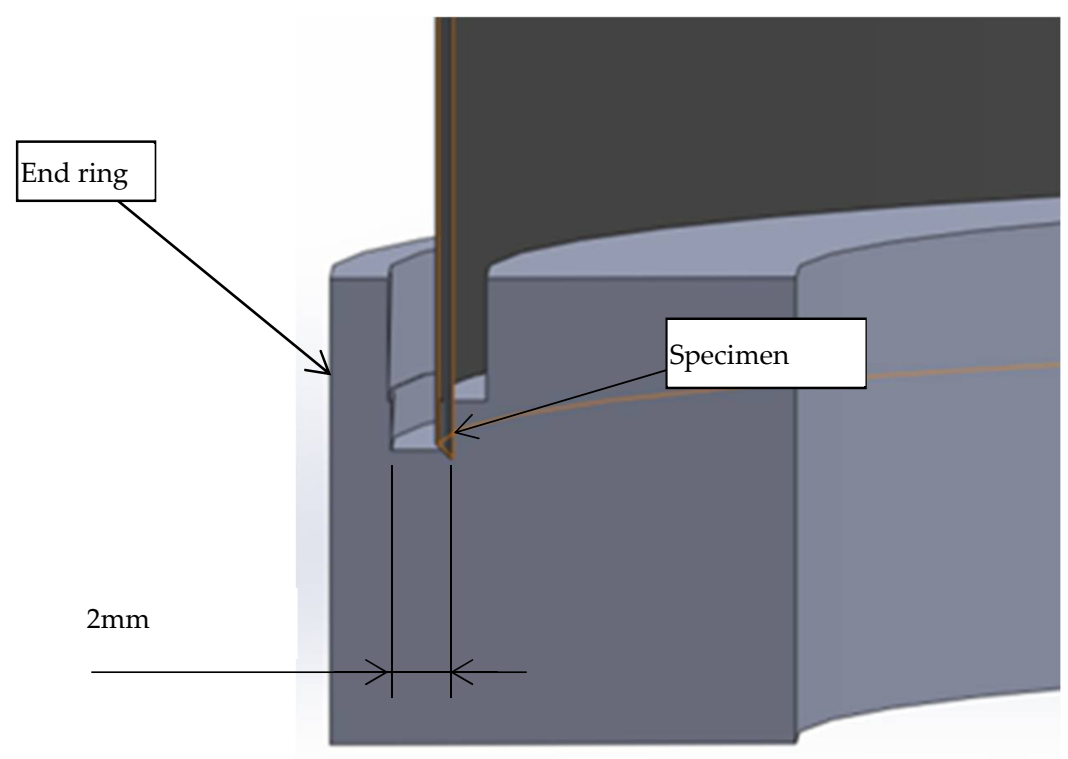

Figure 4. Setting the specimen in the end ring. 


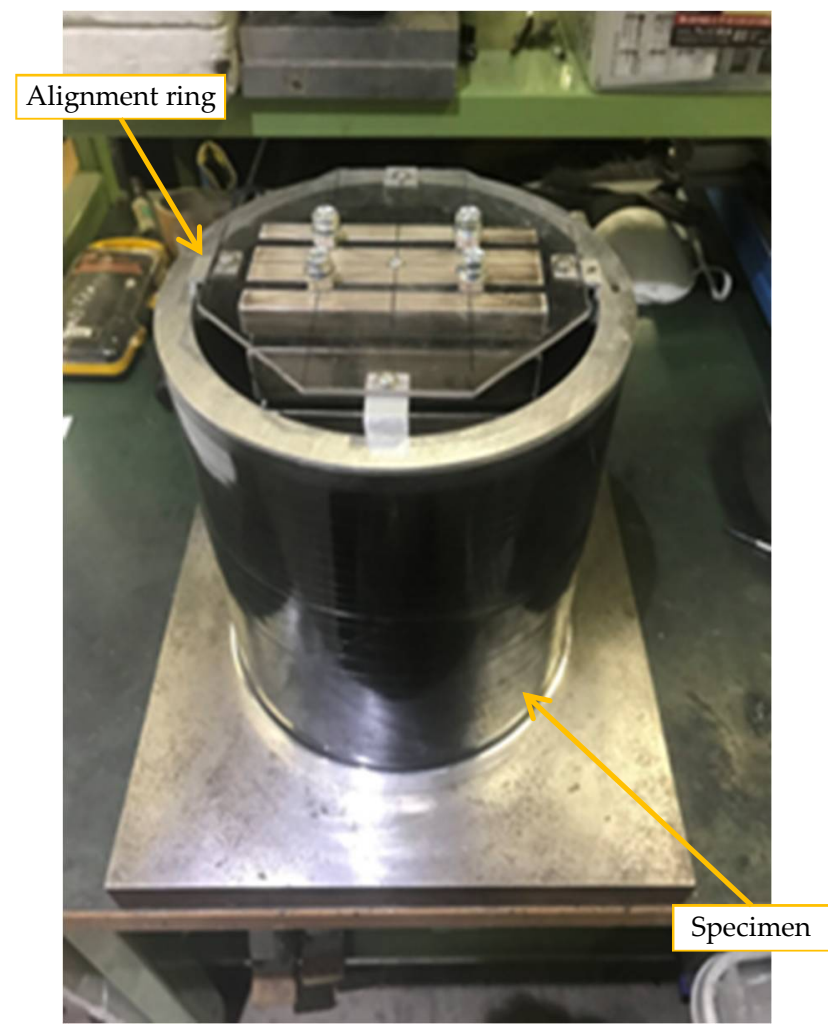

Figure 5. Setting the alignment ring.

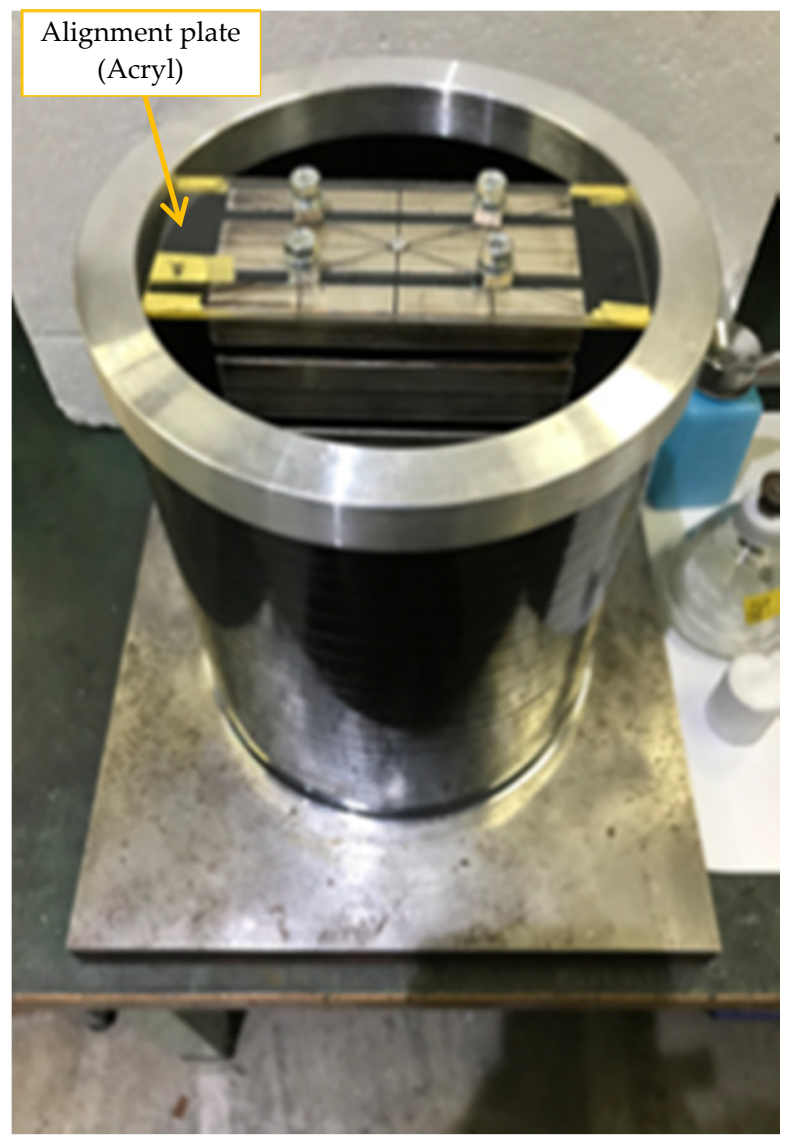

Figure 6. Setting the alignment plate. 


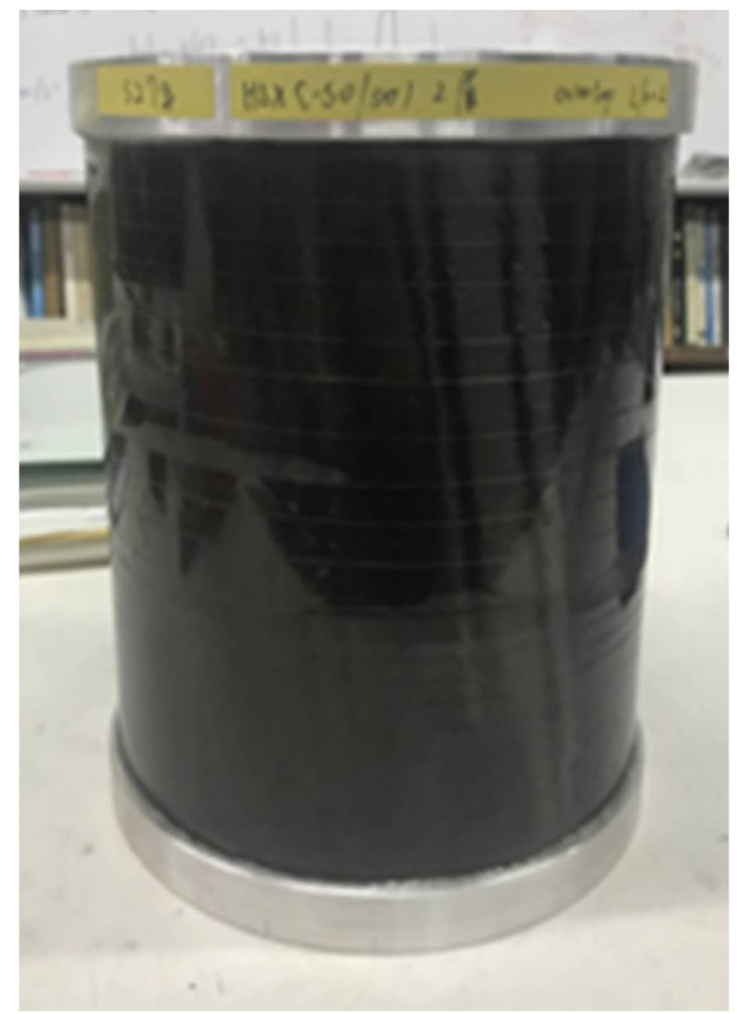

Figure 7. Cylindrical specimen with both end rings.

\section{Shape Measurement Equipment}

Figure 8 shows the shape measurement equipment; the major specifications are listed in Table 3. The equipment consisted of a turntable and a vertical movement head with a laser displacement sensor (LDS). The cylindrical specimen was turned on the turntable and measured by the sensor at different vertical levels. The measurements and movements were controlled by a personal computer. Measurements were taken at 61 points (one point per $6^{\circ}$ ) on ten vertical levels.

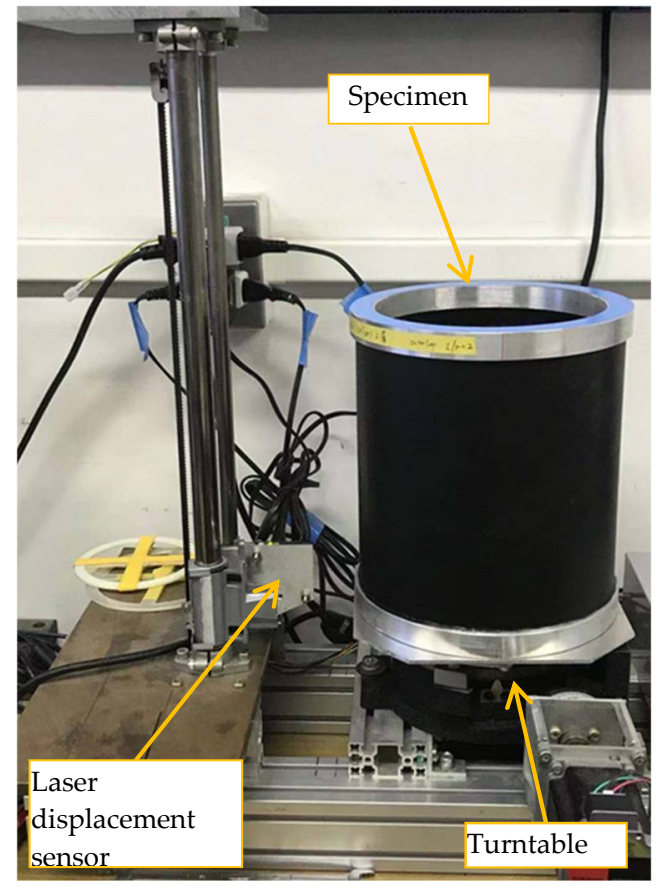

Figure 8. Shape measurement equipment. 
Table 3. Major specifications.

\begin{tabular}{ccc}
\hline \multicolumn{2}{c}{ Measurement range (vertical) } & $388 \mathrm{~mm}$ \\
\hline \multirow{2}{*}{ Laser displacement equipment } & Resolution & $2 \mu \mathrm{m}$ \\
\cline { 2 - 3 } & Range & $\pm 10 \mathrm{~mm}$ \\
\hline \multirow{2}{*}{ Stepper motor } & Vertical & $0.201 \mathrm{~mm} / \mathrm{step}$ \\
\cline { 2 - 3 } & Rotational & $0.02^{\circ} / \mathrm{step}$ \\
\hline
\end{tabular}

\section{Buckling Test}

The buckling test was conducted on the universal testing instrument (Shimadzu AG-I $100 \mathrm{kN}$, load accuracy within $\pm 1 \%$ for an indicated value). To achieve a uniform load, a steel ball and adjustment fixture were used, and the load was applied via a steel plate, as shown in Figure 9. The alignment between the center of the cylindrical specimen and the crosshead of the universal testing instrument was conducted by the crosshead moving down to alignment fixture 1 and checking the offset between the steel ball and the hole of alignment fixture 1 . To easily adjust the cylindrical specimen, fluororesin tape was applied to the baseplate of the universal testing instrument. After adjustment, a 150-N compression load, which is a sufficiently small buckling load, was applied and then removed. The load and displacement curve were then checked, and readjustments were conducted when an anomaly was observed. When an anomaly was not observed, the compression test for buckling was conducted. A crosshead displacement was applied until it reached 1.1 times the buckling displacement; after which, the load was removed. In total, seven buckling load tests were conducted, one without offset (the first test); four with offset $\left(0^{\circ}, 90^{\circ}, 180^{\circ}\right.$, and $270^{\circ}$ ); and two without offset (the last test twice for confirming reproducibility). Two offset amplitudes, $\delta / t=14.6$ and $\delta / t=7.3$, were tested. The cylindrical specimens were thin enough that they were undamaged after they buckled, which enabled the tests to be repeated on them. For the test without an offset, the alignment fixture in Figure 10 was used, while, for the test with an offset, the alignment fixture in Figure 11 was used. To check that there was no anomaly in the inclination of the top of the cylindrical specimen, the displacements of the four corners of the steel plate were measured by using laser displacement sensors (LDSs), as shown in Figure 12. Figure 13 shows an overview of the buckling test.

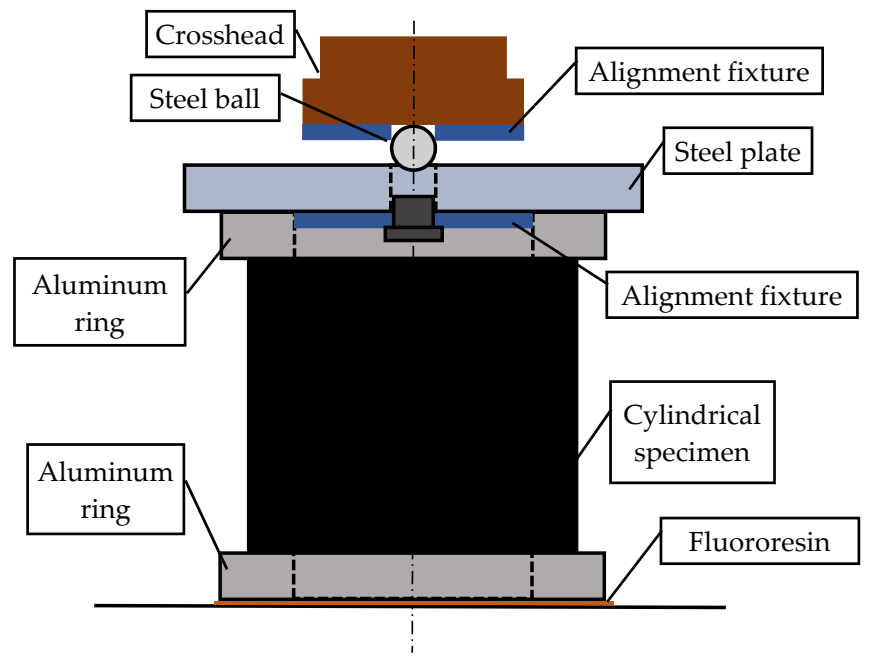

Figure 9. Test setup with the adjustment fixture. 


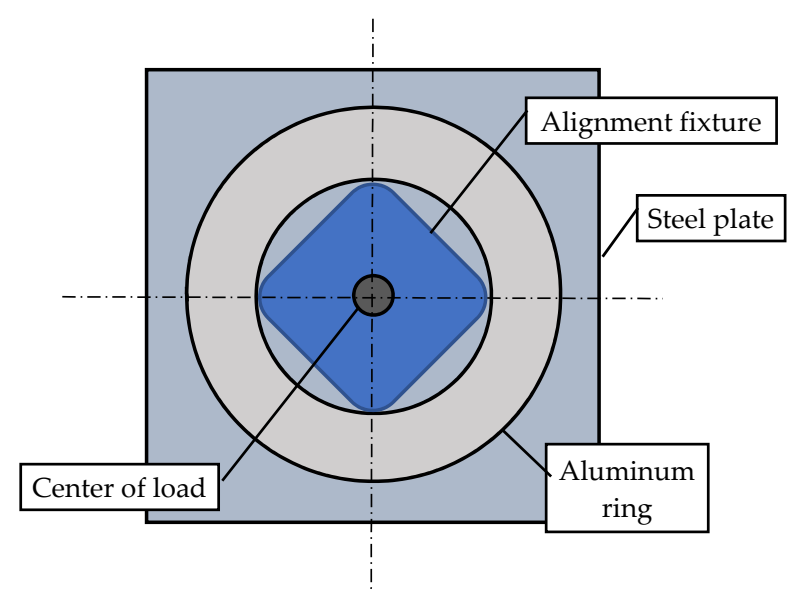

Figure 10. Test without offset.

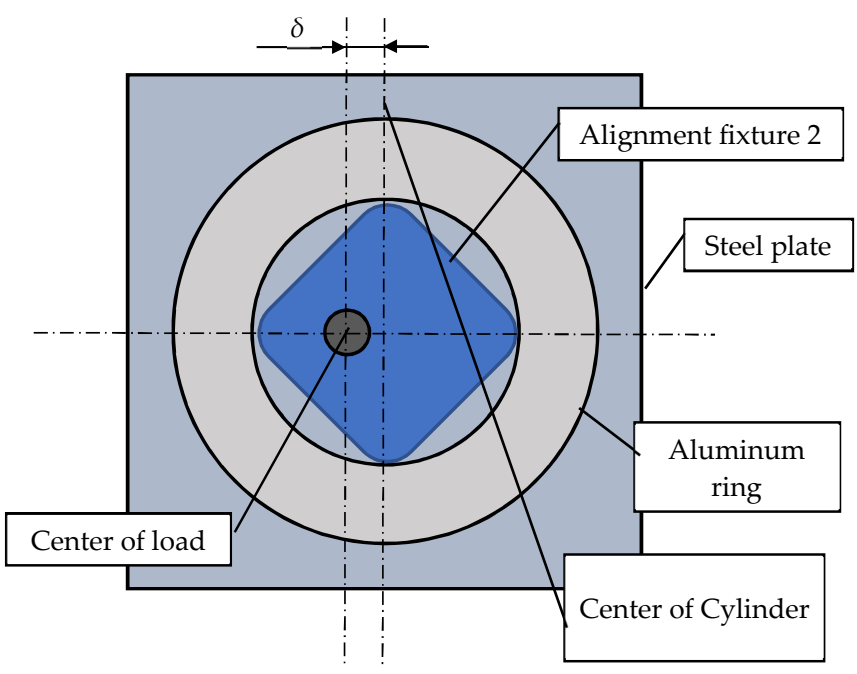

Figure 11. Test with offset.

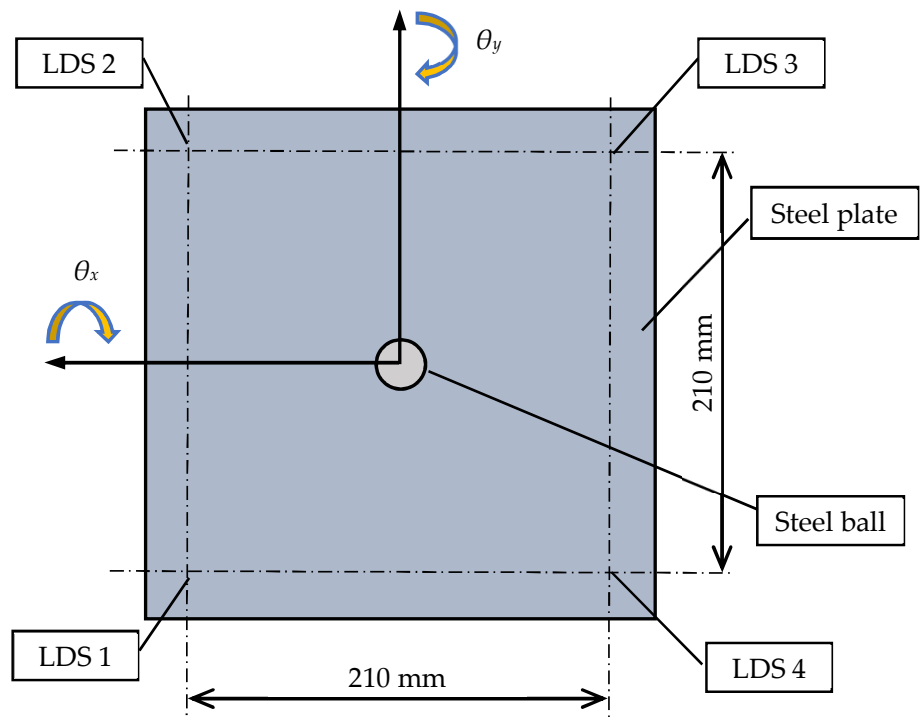

Figure 12. Test setup with the adjustment fixture. LDS: laser displacement sensor. 


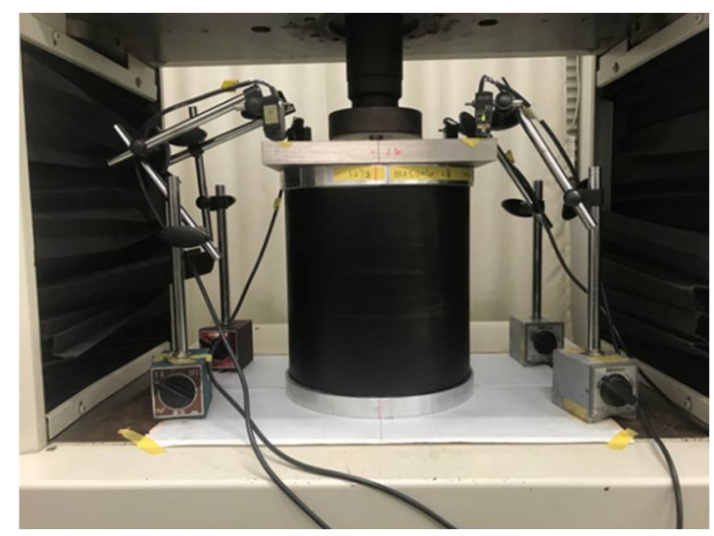

Figure 13. Overview of the buckling test.

\section{Test Comparison between the Mathematical Model and the Test Results and Evaluation}

Figures 14-17 plot buckling loads for the offset and no offset of the load center. The locations of the offset angles $0^{\circ}, 90^{\circ}, 180^{\circ}$, and $270^{\circ}$ are shown in Figure 18 . The origin of the offset angle, $0^{\circ}$ was decided arbitrarily. The theoretical buckling load was calculated by the linear bifurcation theory, including layup anisotropy and transverse shear deformation [19]. The theory was for ideal composite cylinders without shape imperfection. A nonlinear finite element analysis, including the measured shape imperfection [1], can evaluate the effect of the shape imperfection; however, it cannot be used for the prediction of the design use, because it requires the manufacture of a cylinder and measurement of the shape imperfection. Thus, the theoretical method for an ideal cylinder [19] was chosen in this study. The calculated theoretical buckling load was $936 \mathrm{~N}$; thus, the KDFs were $0.43-0.52$. The offset affected the buckling load; however, it was not the main reason for the reduction in the KDF. The buckling load in the cases without offset showed good reproducibility, except for No. 192 with $\delta / t=7.3$ (Figure 17). The first test without offset showed a lower load than in the second and third tests; thus, that was not caused by the degradation of the specimen. Particular angles increased the buckling load: at $180^{\circ}$ in the case of No. 191 with $\delta / t=14.6$ and $\delta / t=7.3$ (Figures 14 and 15) and at $0^{\circ}$ and $270^{\circ}$ in the case of No. 192 with $\delta / t=14.6$ (Figure 16). Figures 18-21 show the shape imperfections on each vertical level of the cylinders before and after the buckling test. No significant changes can be seen between before and after; this also indicates that no damage occurred during the test. Figures 22-25 show the shape measurements after the offset buckling test together with the corresponding buckling load. Figure 22 (for No. 191 with $\delta / t=14.6$ ) shows that the minimum buckling load was obtained at $0^{\circ}$, but Figure 23 (for No. 191 with $\delta / t=7.3$ ) shows that it was obtained at $90^{\circ}$. Similarly, Figure 24 (for No. 192 with $\delta / t=14.6$ ) shows that the minimum buckling load was obtained at $180^{\circ}$, but Figure 25 (for No. 192 with $\delta / t=7.3$ ) shows it was obtained at $90^{\circ}$. These results show that the buckling load was affected not only by the offset direction and shape imperfection but, also, by the offset amplitude. In addition, the minimum buckling load was not always obtained in the offset direction in the case of a large-amplitude shape imperfection, as shown in Figure 25 for the $270^{\circ}$ direction.

Figure 26 plots the KDF over a wide range of $r / t$. The yellow dots at the $r / t=156$ and $r / t=670$ are the previous results [2,3]. The KDFs at the $r / t=893$ are the present results, and they are equal to or lower than the A-basis value obtained by Takano [7], assuming that the KDF is independent from the $r / t$. The following linear regression was used to evaluate the dependency of the KDF on the $r / t$ by using an analysis of variance (ANOVA):

$$
K D F=K F D_{0}+a\left(\frac{r}{t}\right),
$$




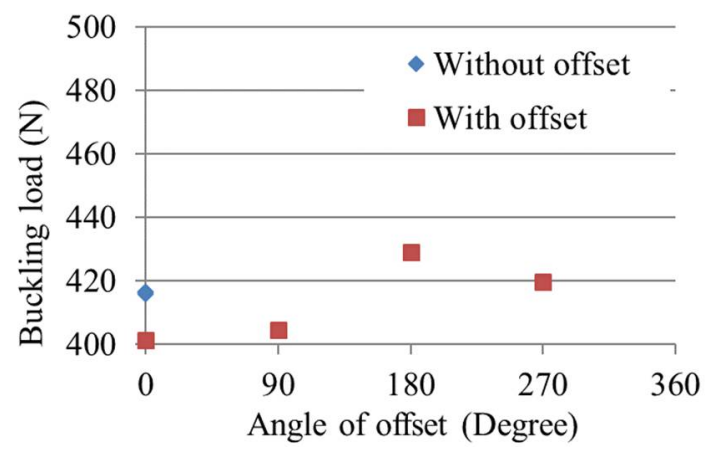

Figure 14. Buckling loads for the offset and no offset for No. 191 with an offset amplitude $\delta / t=14.6$.

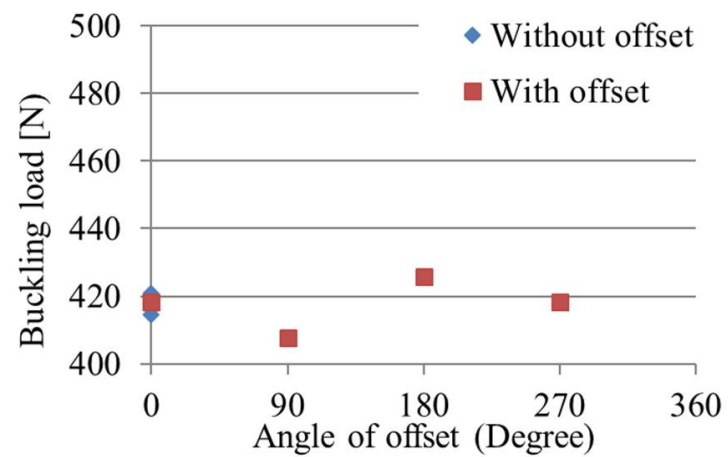

Figure 15. Buckling loads for the offset and no offset for No. 191 with an $\delta / t=7.3$.

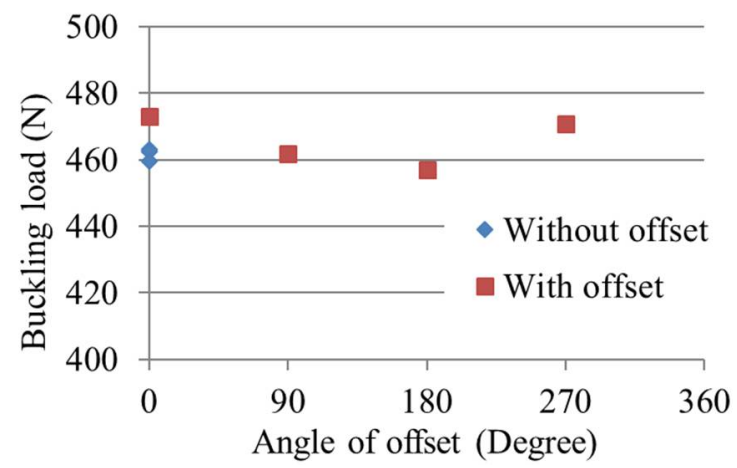

Figure 16. Buckling loads for the offset and no offset for No. 192 with an $\delta / t=14.6$.

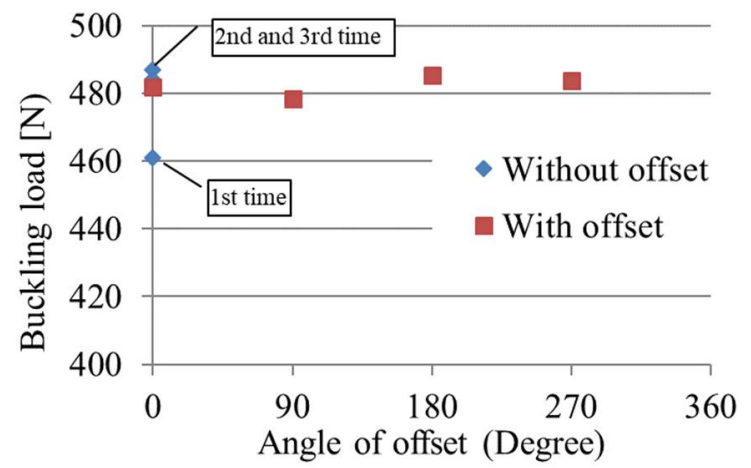

Figure 17. Buckling loads for the offset and no offset for No. 192 with an $\delta / t=7.3$. 


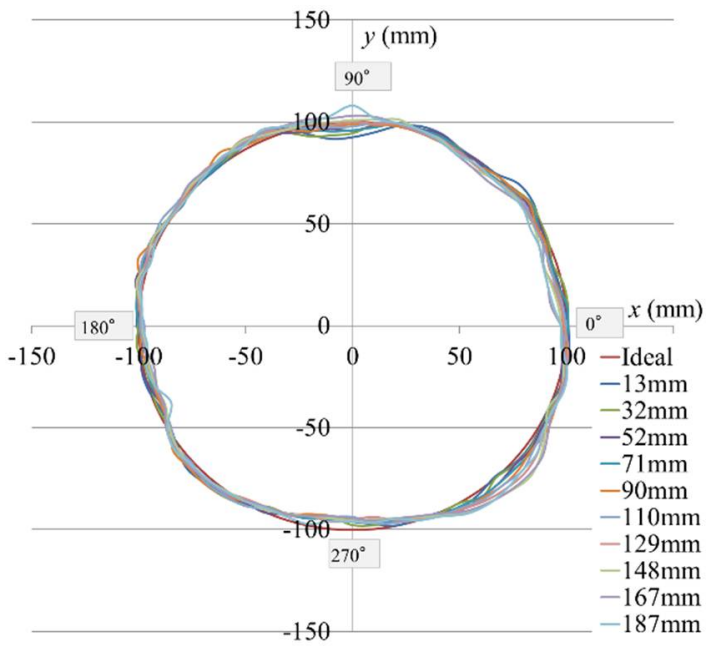

Figure 18. Shape imperfections on each vertical level of No. 191 before the buckling test.

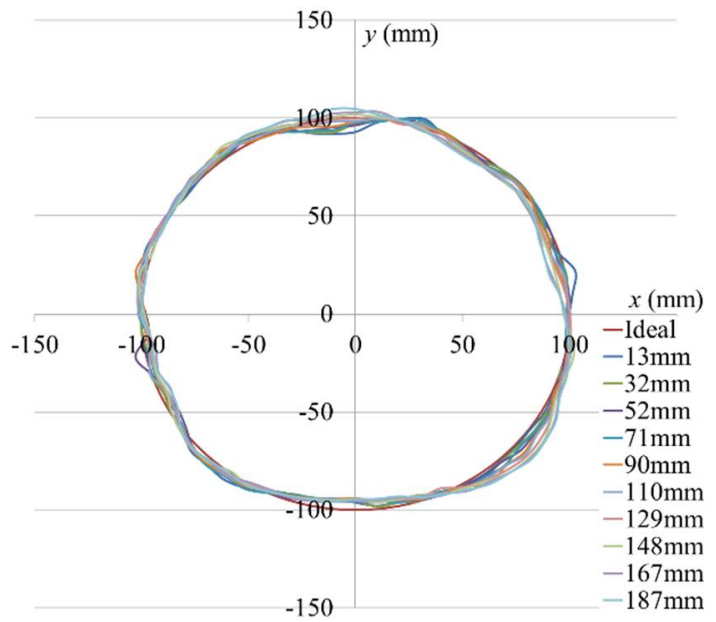

Figure 19. Shape imperfections on each vertical level of No. 191 after the buckling test.

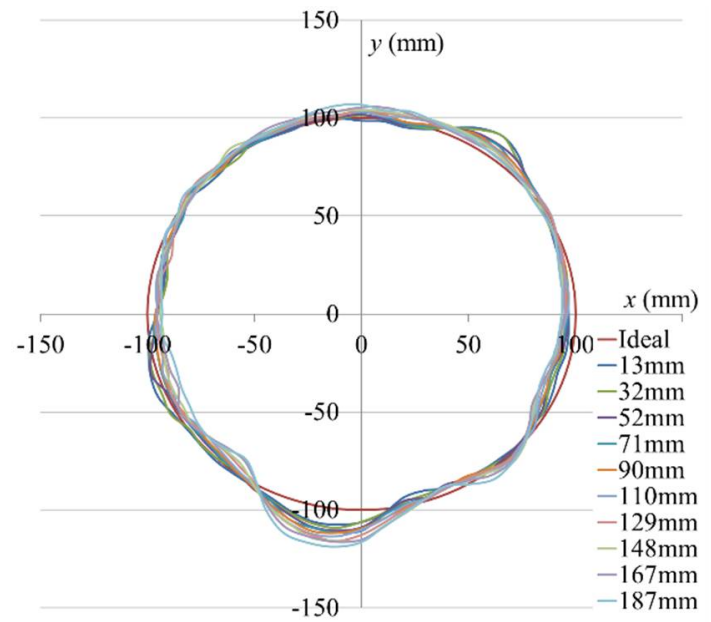

Figure 20. Shape imperfections on each vertical level of No. 192 before the buckling test. 


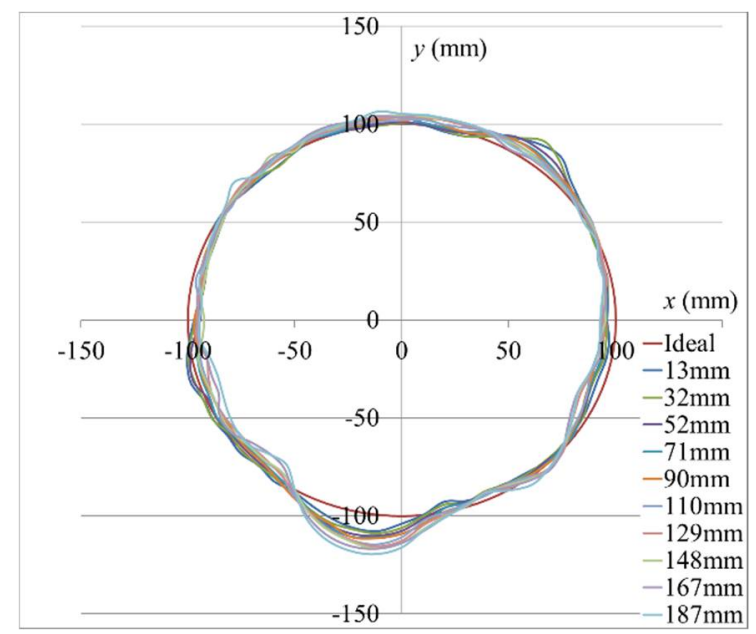

Figure 21. Shape imperfections on each vertical level of No. 192 after the buckling test.

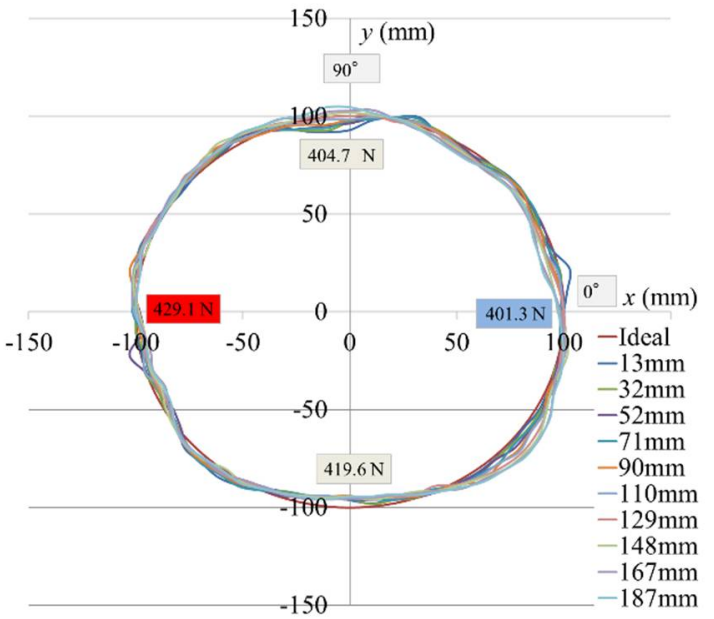

Figure 22. The relationship between the shape imperfection amplitude and buckling load of No. 191; the buckling load on the $\delta / t=14.6$.

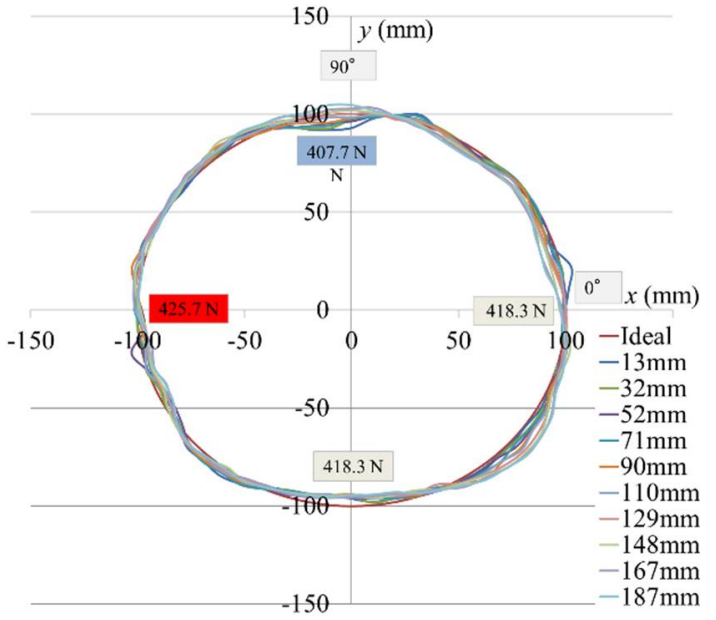

Figure 23. The relationship between the shape imperfection amplitude and buckling load of No. 191; the buckling load on the $\delta / t=7.3$. 


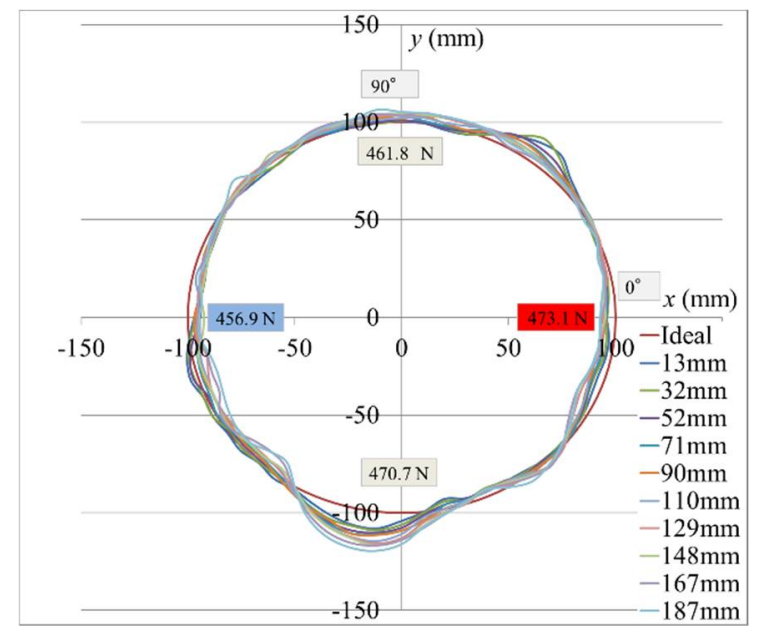

Figure 24. The relationship between the shape imperfection amplitude and buckling load of No. 192; the $\delta / t=14.6$.

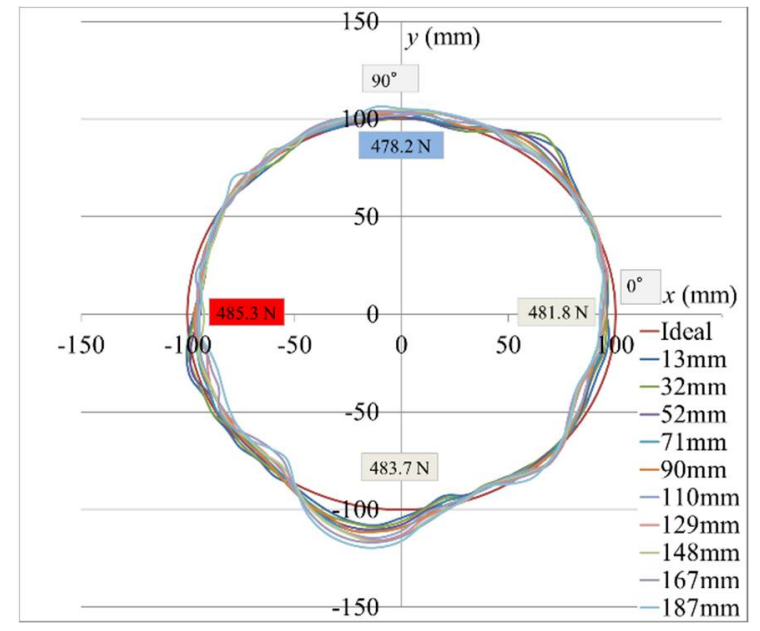

Figure 25. The relationship between the shape imperfection amplitude and buckling load of No. 192; the $\delta / t=7.3$.

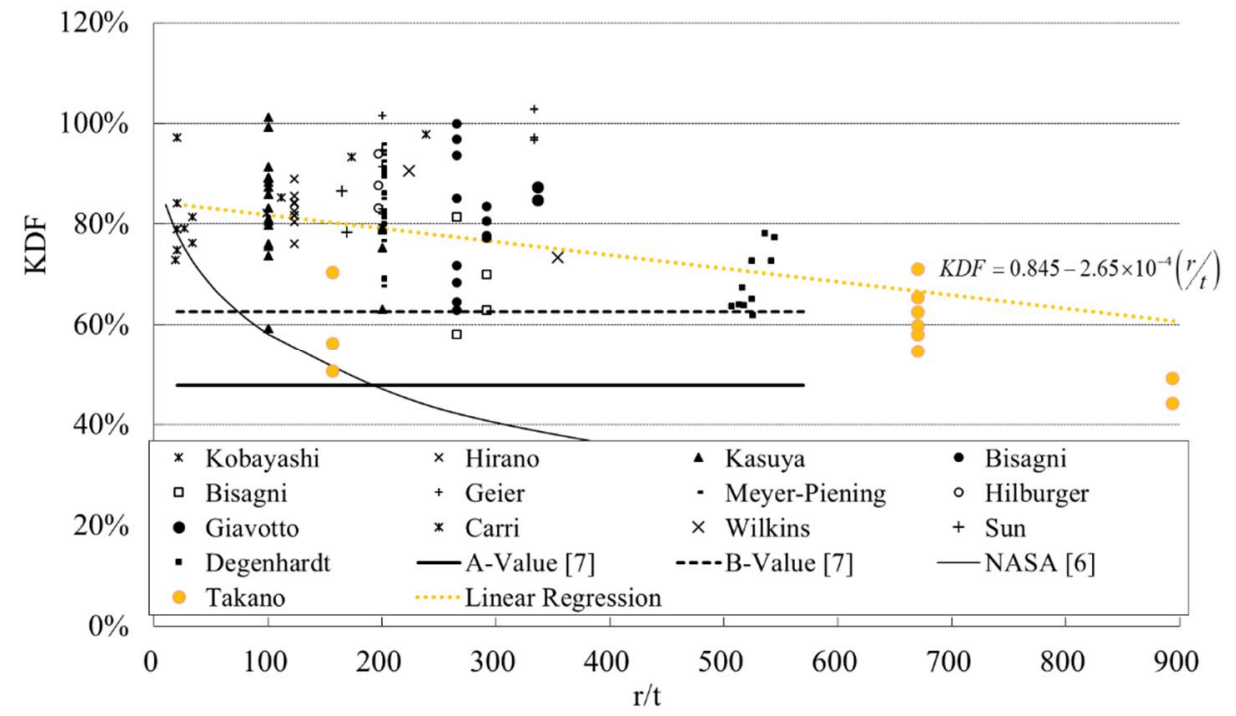

Figure 26. KDF values for a large range of $r / t$. 
Table 4 shows the results of the ANOVA. The coefficient of the $r / t$ is $-2.65 \times 10^{-4}$. It seems small, but the $p$-value is $0.001 \%$, which indicates a statistical significance, because it is much smaller than $1 \%$. Usually, a $p$-value smaller than $1 \%$ indicates a high statistical significance. The linear regression is plotted in Figure 26. The line is higher than the KDFs at the $r / t=893$; thus, it cannot be used as the design criterion. A statistically lower-bound curve with linear regression can be easily plotted, but a suitable regression form should reflect the physical reason behind the reduction. A reason could not be obtained in this study, because only two specimens were tested; thus, more tests will be required.

Table 4. Analysis of variance (ANOVA).

\begin{tabular}{cccc}
\hline Term & Coef. & Std. Dev. & $p$-Value \\
\hline Intercept, $K D F_{0}$ & 0.845 & 0.015729 & $0.000 \%$ \\
$r / t, a$ & $-2.65 \times 10^{-4}$ & $5.88 \times 10^{-5}$ & $0.001 \%$ \\
\hline
\end{tabular}

\section{Conclusions}

Buckling tests were performed on composite cylindrical shells with large radius-tothickness ratios. The shape imperfections before and after the tests were measured, and the buckling loads in the case of an offset load or no offset to the load were measured. The KDFs ranged from 0.43 through 0.52 in the tests; however, the reduction in the KDF by the offset was insignificant. In addition, the relationship between the offset amplitude and offset direction was also insignificant. These results indicate that the major reason for the reduction in the KDF was not load offset or local shape imperfection. The obtained KDFs for the $r / t=893$ indicated a dependency between the KDF and $r / t$. An ANOVA by linear regression indicated that the KDF decreased with the increasing $r / t$. Thus, to obtain a lower-bound curve of the KDF, the major reason for reduction in the KDF remains to be revealed.

Author Contributions: Conceptualization, A.T.; methodology, A.T.; software, A.T.; validation, A.T. and J.B.; formal analysis, A.T. and J.B.; investigation, J.B.; writing-original draft preparation, A.T.; and writing-review and editing, R.K. and T.M. All authors have read and agreed to the published version of the manuscript.

Funding: This research received no external funding.

Institutional Review Board Statement: Not applicable.

Informed Consent Statement: Not applicable.

Data Availability Statement: The data presented in this study are available on request from the corresponding author.

Conflicts of Interest: The authors declare no conflict of interest.

\section{References}

1. Hilburger, M.W.; Nemeth, M.P.; Starnes, J.H., Jr. Shell Buckling Design Criteria Based on Manufacturing Imperfection Signatures. AIAA J. 1999, 37, 276-278.

2. Takano, A. Buckling Experiment on Anisotropic Long and Short Cylinders. Adv. Technol. Innov. 2016, 1, $25-27$.

3. Takano, A. Buckling Test Composite Cylindrical Shells with Oval Imperfection Under Axial Compression. In Proceedings of the European Conference on Spacecraft Structures, Materials and Environmental Testing (ECSSMET), NoordwijK, The Netherlands, 28 May-1 June 2018.

4. Bao, J.; Takano, A. Influence on Buckling Strength by the Axial Shape Imperfection of the CFRP Cylinder. In Proceedings of the JSASS/JSME/JAXA Structures Conference, Nagano, Japan, 7-9 August 2019. 1B09. (In Japanese)

5. Wagner, H.N.R.; Hühne, C.; Elishakoff, I. Probabilistic and Deterministic Lower-Bound Design Benchmarks for Cylindrical Shells under Axial Compression. Thin Walled Struct. 2020, 146, 106451. [CrossRef]

6. National Aeronautics and Space Administration. Buckling of Thin-Walled Circular Cylinders; NASA SP-8007; NASA: Washington, DC, USA, 1968.

7. Takano, A. Statistical Knockdown Factors of Buckling Anisotropic Cylinders Under Axial Compression. J. Appl. Mech. 2012, 79, 051004. [CrossRef] 
8. Wagner, R.H.N.; Hühne, C.; Niemann, S.; Khakimova, R. Robust design criterion for axially loaded cylindrical shells-Simulation and Validation. Thin Walled Struct. 2017, 115, 154-162. [CrossRef]

9. Wagner, R.H.N.; Hühne, C. Robust knockdown factors for the design of cylindrical shells under axial compression-potentials, practical application and reliability analysis. Int. J. Mech. Sci. 2018, 135, 410-430. [CrossRef]

10. Tobias, S.H.; Dieter, K. The Influence of Geometric Imperfections of Different Tolerance Levels on the Buckling Load of Unstiffened CFRP Cylindrical Shells. In Proceedings of the Twenty-Second International Conference on Composite Materials (ICCM22), Melbourne, Australia, 11-16 August 2019.

11. Wagner, H.N.R.; Sosa, E.M.; Ludwig, T.; Croll, J.G.A.; Hühne, C. Robust design of imperfection sensitive thin-walled shells under axial compression, bending or external pressure. Int. J. Mech. Sci. 2019, 156, 205-220. [CrossRef]

12. Arbelo, M.A.; Zimmermann, R.; Castro, S.G.P.; Degenhardt, R. Comparison of new Design Guidelines for Composite Cylindrical Shells prone to Buckling. In Proceedings of the 9th International Conference on Composite Science and Technology, Sorrento, Italy, 24-26 April 2013.

13. Wagner, H.N.R.; Petersen, E.; Khakimova, R.; Hühne, C. Buckling Analysis of an Imperfection-Insensitive Hybrid Composite Cylinder under axial Compression-Numerical Simulation, Destructive and Nondestructive Experimental Testing. Compos. Struct. 2019, 225, 111152. [CrossRef]

14. Khakimova, R.; Castro, S.G.P.; Wilckens, D.; Rohwer, K.; Degenhardt, R. Buckling of Axially Compressed CFRP Cylinders with and without Additional Lateral load: Experimental and Numerical Investigation. Thin Walled Struct. 2017, 19, 178-189. [CrossRef]

15. Sahu, V.; Gayathri, V. Strength Studies of Dadri Fly Ash Modified with Lime Sludge-A Composite Material. Int. J. Eng. Technol. Innov. 2014, 4, 161-169.

16. Liu, C.M.; Chiang, M.S.; Chuang, W.C. Lean Transformation for Composite-Material Bonding Processes. Int. J. Eng. Technol. Innov. 2012, 2, 48-62.

17. Chang, C.Y. Segmented Compression Molding for Composite Manufacture. Proc. Eng. Technol. Innov. 2017, 5, 41-44.

18. Chang, C.Y.; Chen, W.R. Experimental Study of Progressive Compression Method of Resin Delivery in Liquid Composite Molding. Proc. Eng. Technol. Innov. 2016, 2, 23-25.

19. Takano, A. Simple Closed-Form Solution for the Buckling of Moderately Thick Anisotropic Cylinders. Trans. Jpn. Soc. Aeronaut. Space Sci. Aerosp. Technol. Jpn. 2012, 10, 17-26. [CrossRef] 